\title{
Markers of anti-malarial drug resistance in Plasmodium falciparum isolates from Swaziland: identification of pfmdr1-86F in natural parasite isolates
}

\author{
Sabelo V Dlamini ${ }^{1,2}$, Khalid Beshir ${ }^{2}$, Colin J Sutherland ${ }^{2 *}$
}

\begin{abstract}
Background: The development of Plasmodium falciparum resistance to chloroquine (CQ) has limited its use in many malaria endemic areas of the world. However, despite recent drug policy changes to adopt the more effective artemisinin-based combination (ACT) in Africa and in the Southern African region, in 2007 Swaziland still relied on CQ as first-line anti-malarial drug.

Methods: Parasite DNA was amplified from P. falciparum isolates from Swaziland collected in 1999 (thick smear blood slides) and 2007 (filter paper blood spots). Markers of CQ and sulphadoxine-pyrimethamine (SP) resistance were identified by probe-based $\mathrm{QPCR}$ and DNA sequencing.

Results: Retrospective microscopy, confirmed by PCR amplification, found that only six of 252 patients treated for uncomplicated malaria in 2007 carried detectable $P$. falciparum. The pfcrt haplotype 72C/73V/74l/75E/76T occurred at a prevalence of $70 \%(n=64)$ in 1999 and $83 \%(n=6)$ in 2007. Prevalence of the $p f m d r 1-86 \mathrm{~N}$ allele was $24 \%$ in 1999 and 67\% in 2007. A novel substitution of phenylalanine for asparagine at codon 86 of pfmdr1 (N86F) occurred in two of 51 isolates successfully amplified from 1999. The pfmdr1-1246Y allele was common in 1999, with a prevalence of 49\%, but was absent among isolates collected in 2007. The 86N/184F/1246D pfmdr1 haplotype, associated with enhanced parasite survival in patients treated with artemether-lumefantrine, comprised 8\% of 1999 isolates, and 67\% among 2007 isolates. The pfdhfr triple-mutant 16C/511/59R/108N/164l haplotype associated with pyrimethamine resistance was common in both $1999(82 \%, \mathrm{n}=34)$ and $2007(50 \%, \mathrm{n}=6)$, as was the wild-type 431//436S/437A/540K/581A/613A haplotype of pfdhps (100\% and 93\% respectively in 1999 and 2007). The quintuple-mutant haplotype pfdhfr/pfdhps-CIRNI/ISGEAA, associated with high-level resistance to SP, was rare (9\%) among 1999 isolates and absent among 2007 isolates.

Conclusions: The prevalence of pfcrt and pfmdr1 alleles reported in this study is consistent with a parasite population under sustained CQ drug pressure. The low prevalence of dhps-437G and dhps-540E mutations (ISGEAA) and the rarity of quintuple-mutant haplotype pfdhfr/pfdhps-CIRNI/ISGEAA suggest that SP retains some efficacy in Swaziland. Anti-malarial policy changes in neighbouring countries may have had an impact on the prevalence of molecular markers of anti-malarial resistance in Swaziland, and it is hoped that this new information will add to understanding of the regional anti-malarial resistance map.
\end{abstract}

\footnotetext{
* Correspondence: colin.sutherland@|shtm.ac.uk

${ }^{2}$ Department of Infectious and Tropical Diseases, London School of Hygiene and Tropical Medicine, Keppel St, London WC1E 7HT, UK
} 


\section{Background}

The emergence and spread of drug resistant malaria poses the greatest challenge to the control and elimination of malaria in Swaziland. Despite reports of chloroquine failure suspected to be a result of drug resistance in the 1980s [1], CQ has remained the first-line drug for treatment of uncomplicated Plasmodium falciparum malaria in Swaziland. The combination of sulphadoxine and pyrimethamine (SP) has been an effective and affordable alternative single dose treatment for CQresistant parasites since its first introduction to Africa in the 1960s. Use of SP increased rapidly in countries with CQ resistance over the next 30 years. As a result, resistance to SP is now globally widespread [2], leading most malaria endemic countries in Africa to abandon SP alone as first-line treatment. In Swaziland, SP was introduced in 1993 as a second-line treatment for uncomplicated malaria following reports of $\mathrm{CQ}$ failure in Mozambique [3-5], South Africa (KwaZulu-Natal) [6] and Swaziland [1]. To this day, SP remains a secondline anti-malarial in Swaziland despite its withdrawal as a first-line anti-malarial in KwaZulu-Natal (2001) and Mozambique (2002). Resistance to CQ is associated with polymorphisms in the pfcrt and pfmdr1 genes, and resistance to SP with $p f d h f r$ and $p f d h p s$ polymorphisms. No data are available concerning the diversity of these loci in Swaziland.

The mutation at codon 76 of the pfcrt gene, where lysine is replaced by threonine (K76T) has been strongly associated with $P$. falciparum resistance to CQ and subsequent treatment failure [7]. Mutations in the $p f c r t$ gene at codons other than $\mathrm{K} 76 \mathrm{~T}$ are said to modulate CQ resistance and/or compensate deleterious effects of K76T mutations [8]. Mutations in the pfmdr1 gene (N86Y, Y184F, S1034C, N1042D and D1246Y) have been reported to modulate the level of CQ resistance [9-11]. Recent studies have further associated some alleles of the $p f m d r 1$ gene with decreased susceptibility to artemisinin-containing drugs. Artemether-lumefantrine (AL) is currently the most favoured combination therapy against uncomplicated Plasmodium falciparum malaria in southern Africa. However, in vivo studies of AL-treated patients have shown enhanced survival of parasites carrying the $p f m d r 1$ polymorphisms $(86 \mathrm{~N}$, $184 \mathrm{~F}$ and $1246 \mathrm{D}$ ) and selection against the YYY haplotype $[12,13]$. Studies have also reported an increased pfmdr1 copy number in parasites of Asian origin following AL treatment [14]. Selection of the NFD haplotype and increased $p f m d r 1$ copy number could result in reduced susceptibility of parasites to AL and further investigation of $p f m d r 1$ in areas implementing AL treatment policy are clearly needed.
Resistance to SP has been shown to occur following changes in the amino acid sequences of the dihydrofolate reductase (DHFR) [15] and dihydropteroate synthase (DHPS) [16] enzymes, with both in vitro and in vivo studies finding associations between mutations in the $d h f r$ gene of $P$. falciparum and resistance to pyrimethamine $[17,18]$ and between mutations in the pfdhps gene and resistance to sulphadoxine $[19,20]$. The level of resistance to SP has been shown to increase with accumulation of mutations in codons 51, 59, 108 and 164 in pfdhfr and in codons 437 and 540 in pfdhps [21,22]; the contribution to resistance of mutations at positions 431, 436, 581 and 613 of pfdhps remains unclear [23].

This report describes molecular screening of 79 isolates from Swaziland collected in 1999 and 2007. Resistance-associated polymorphisms in the $p f c r t, p f m d r 1$, $p f d h f r$ and $p f d h p s$ genes were determined by multiplex qPCR and direct DNA sequencing of conventional PCR products.

\section{Methods}

\section{Study samples}

Two hundred and fifty-two blood samples were collected from patients clinically diagnosed with uncomplicated malaria in eight health centres in the malaria endemic lowveld of Swaziland between 01 February and 30 April, 2007. Only six of these patients were confirmed microscopy positive for P. falciparum by two laboratory technicians working independently. Twentyfour of the microscopy-negative samples $(10 \%)$ were randomly selected to further confirm the validity of the laboratory confirmation by PCR. Seventy-three glass microscope slides with Giemsa-stained thick blood smear samples from confirmed malaria cases in 1999 were also obtained for the analysis. These came from Simunye, on the northern lowveld of Swaziland and Big Bend in the Ubombo Ranches on the southern lowveld of Swaziland. The two centres attract patients from the whole malarious region of Swaziland, with Simunye providing diagnosis and treatment for patients from the northern part and Big Bend for patients from the south.

The study was approved by the London School of Hygiene and Tropical Medicine Ethics Committee and the Ministry of Health and Social Welfare (Swaziland) Ethics Committee. Written informed consent was obtained from all participants or parents/guardians in the case of children.

\section{Isolation of DNA}

Parasite genomic DNA was extracted from dried filter papers using the Chelex ${ }^{\circ} 100$ method according to 
methods described elsewhere [24]. Briefly, the discs were lysed in $5 \%$ saponin in $1 \times \mathrm{PBS}$ and incubated at $37^{\circ} \mathrm{C}$ overnight. The samples were centrifuged, saponin and debris were removed using a vacuum pump, and the pellets washed twice in buffered saline. The samples were then suspended in $6 \%$ Chelex 100 resin and heat-sealed in deep 96-well plates. The samples were incubated in boiling water for 20 - 25 minutes and then centrifuged to remove resin. Approximately $100 \mu \mathrm{l}$ of supernatant containing DNA was removed and stored at $-20^{\circ} \mathrm{C}$.

Parasite DNA was isolated from stained thick blood smears using the QIAmp Mini Blood Purification kit (QIAGEN, UK) following the manufacturer's instructions. A sterile scalpel was used to spread lysis buffer over the blood and to scrape material into a $1.5 \mathrm{ml}$ microcentrifuge tube for further processing. The DNA was finally collected in $100 \mu \mathrm{l}$ of elution buffer, centrifuged at $8000 \mathrm{~g}$ for $1 \mathrm{~min}$ and stored at $-20^{\circ} \mathrm{C}$.

\section{Parasite genotyping by PCR \\ pfort}

The genotype of the pfcrt gene for polymorphisms C72S, M74I, N75E, and K76T was determined in at least two multiplex real-time qPCR runs with full agreement using the Rotorgene 3000 platform (Corbett Research, Australia). Primer sets and cycling conditions were as described previously [25], in the presence of the doublelabelled probes representing CVIET, CVMNK and SVMNT haplotypes. 3D7, Dd2 and 7G8 DNA obtained from the Malaria Research \& Reference Reagent Resource (MR4, Manassas, Vermont, USA) was used to provide sequence-specific positive controls and nuclease-free water was included as a negative control.

\section{pfmdr1}

Amplification of the $p f m d r 1$ gene was initially performed in two fragments (FR1 and FR2). Primers and cycling conditions used for FR1 and FR2 are described elsewhere [13]. For some samples, FR2 amplification was unsuccessful, and so two smaller fragments, FR3 and FR4, encompassing the codons of interest in FR2, were amplified. Primers and cycling conditions for FR3 and FR4 are listed in Table 1.

\section{pfdhfr and pfdhps}

Amplification of $p f d h f r$ and $p f d h p s$ genes involved primers and cycling conditions described elsewhere [23,26]. All amplicons of the pfmdrl, pfdhfr and pfdhps genes were re-amplified in a nested PCR step. The PCR products of nested reactions were separated by gel electrophoresis on a $1.2 \%$ agarose gel stained with ethidium bromide to identify amplified bands of DNA under ultra-violet illumination. Amplicons from nested PCR reactions were purified using the QIAquick PCR Purification Kit (QIAGEN, UK) according to manufacturer's instructions and subjected to di-deoxy fluorescent sequencing (BigDye 3.1, Applied Biosystems, UK) using conditions and sequencing primer pairs described elsewhere $[13,25,26]$ or as shown in Table 1 (pfmdr1 FR3 and FR4). The sequence of amplified DNA products was determined using ABI PRISM 3730 Genetic Analyser (Applied Biosystems, UK). Chromas software (Technelysium, Australia) was used to analyse the sequence results. The DNA sequence was compared with reference sequence of the $p f m d r 1, p f d h f r$ and $p f d h p s$ portions of the P. falciparum 3D7 clone using BLAST similarity alignment (Washington University, USA). Appropriate control DNA samples with known pfmdr1, pfdhfr and

Table 1 pfmdr1 PCR primer sequences and reaction conditions used in Fragments 3 and 4 amplification reactions

\begin{tabular}{|c|c|c|c|c|c|}
\hline Gene Fragment & Primer name & & Primer Sequence & Codons & PCR Cycling conditions \\
\hline \multicolumn{6}{|l|}{ Fragment 3} \\
\hline \multirow[t]{2}{*}{ Primary FR3 } & MDRF3N1 & $\mathrm{F}$ & 5'-GCATTITATAATATGCATACTG-3' & 1034,1042 & $94^{\circ} \mathrm{C} 3 \mathrm{~min} /\left[94^{\circ} \mathrm{C} 30 \mathrm{~s}-56^{\circ} \mathrm{C} 60 \mathrm{~s} 65^{\circ} \mathrm{C} 50 \mathrm{~s}\right]$ \\
\hline & MDRF3R1 & $\mathrm{R}$ & 5'-GGATTTCATAAAGTCATCAAC-3' & & $\times 30$ cycles \\
\hline \multirow[t]{2}{*}{ Nested FR3 } & MDRF3N2 & $\mathrm{F}$ & 5'-GGTTTAGAAGATTATTTCTGTA-3' & & $65^{\circ} \mathrm{C} 5 \mathrm{~min} / 15^{\circ} \mathrm{C} 5 \mathrm{~min}$ \\
\hline & MDRF3R1 & $\mathrm{R}$ & 5'-GCATTITATAATATGCATACTG-3' & & \\
\hline \multicolumn{6}{|l|}{ Fragment 4} \\
\hline \multirow[t]{2}{*}{ Primary FR4 } & MDRF4N1 & $\mathrm{F}$ & 5'-CAAACCAATCTGGATCTGCAG-3' & 1246 & $94^{\circ} \mathrm{C} 3 \mathrm{~min} /\left[94^{\circ} \mathrm{C} 30 \mathrm{~s}-55^{\circ} \mathrm{C} 60 \mathrm{~s}-65^{\circ} \mathrm{C} 40 \mathrm{~s}\right]$ \\
\hline & MDRF4R1 & $\mathrm{R}$ & 5'-CAATGTTGCATCTTCTCTTCC-3' & & $\times 30$ cycles \\
\hline \multirow[t]{2}{*}{ Nested FR4 } & MDRF4N2 & $\mathrm{F}$ & 5'-GATCTGCAGAAGATTATACTG-3' & & $65^{\circ} \mathrm{C} 5 \mathrm{~min} / 15^{\circ} \mathrm{C} 5 \mathrm{~min}$ \\
\hline & MDRF4R1 & $\mathrm{R}$ & 5'-CAATGTTGCATCTTCTCTTCC-3' & & \\
\hline \multicolumn{6}{|l|}{ Sequencing } \\
\hline \multirow[t]{2}{*}{ FR3 } & MDRF3N2 & $\mathrm{F}$ & 5'-GGTTTAGAAGATTATTTCTGTA-3' & & $96^{\circ} \mathrm{C} 1 \mathrm{~min}$ \\
\hline & MDRF3R1 & R & 5'-GCATTITATAATATGCATACTG-3' & & {$\left[96^{\circ} \mathrm{C} 30 \mathrm{~s}-50^{\circ} \mathrm{C}-60^{\circ} \mathrm{C} 4 \mathrm{~min}\right]$} \\
\hline \multirow[t]{2}{*}{ FR4 } & MDRF4N2 & $\mathrm{F}$ & 5'-GATCTGCAGAAGATTATACTG-3' & & $\times 26$ cycles \\
\hline & MDRF4R1 & $\mathrm{R}$ & 5'-CAATGTTGCATCTTCTCTTCC-3' & & \\
\hline
\end{tabular}

FR - Fragment F - forward R - Reverse

NB: Cycling conditions are the same for primary and nested PCRs. 
pfdhps sequences were used in parallel with field-collected parasite isolates in every step of the protocol.

\section{Results}

\section{Pfcrt polymorphisms}

The pfcrt 72-76 haplotypes CVIET, CVMNK and SVMNT were successfully identified in 70 DNA samples. Five (83\%) of the six 2007 samples and 45 (70\%) of the sixty-four 1999 samples carried the CVIET haplotype. Only one (17\%) of the 2007 samples carried the wild type CVMNK haplotype while it occurred alone in five $(8 \%)$ of the 64 successfully amplified 1999 samples
(Table 2). Mixed haplotype infections (CVMNK/CVIET) were found in 14 (22\%) of the 1999 samples. No parasites carried mixed CVIET/CVMNK haplotypes among the 2007 samples. The SVMNT haplotype was not found in any of the isolates. These results suggest that the prevalence of the CVIET haplotype remained high between 1999 and 2007.

\section{Pfmdr1 polymorphisms}

Fifty samples from 1999 were successfully genotyped for pfmdr1 at codons 86, 184, 1034, 1042 and 1246, as were all 2007 samples. No mutations were found in codons

Table 2 Prevalence of pfcrt, pfmdr1, pfdhfr and pfdhps haplotypes in Swaziland: 1999 and 2007

\begin{tabular}{|c|c|c|c|c|c|}
\hline \multirow[t]{2}{*}{ Gene } & \multirow[t]{2}{*}{$\mathrm{n}$} & \multicolumn{2}{|c|}{ Genotype/Haplotype } & \multicolumn{2}{|c|}{ Prevalence } \\
\hline & & & & 1999 & 2007 \\
\hline \multirow{3}{*}{$\begin{array}{l}\text { pfcrt } \\
\text { Amino acids: } \\
72-76\end{array}$} & 64 (1999) & CVMNK & wild-type & $5(8 \%)$ & $1(17 \%)$ \\
\hline & $6(2007)$ & CVIET & mutant & $45(70 \%)$ & $5(83 \%)$ \\
\hline & & CVMNK/CVIET & mixed & $14(22 \%)$ & $0(0 \%)$ \\
\hline \multirow{16}{*}{$\begin{array}{l}\text { pfmdr1 } \\
\text { Amino acids: } \\
86,184,103,1042,1246 .\end{array}$} & 51 (1999) & $86 \mathrm{~N}$ & wild-type & $12(24 \%)$ & $4(67 \%)$ \\
\hline & $6(2007)$ & $86 \mathrm{Y}$ & mutant & 37 (73\%) & $2(33 \%)$ \\
\hline & & $86 \mathrm{~F}$ & mutant & $2(4 \%)$ & $0(0 \%)$ \\
\hline & 50 (1999) & $184 Y$ & wild-type & $39(78 \%)$ & $2(33 \%)$ \\
\hline & $6(2007)$ & $184 \mathrm{~F}$ & mutant & $11(22 \%)$ & $4(67 \%)$ \\
\hline & 51 (1999) & $1246 D$ & wild-type & $25(51 \%)$ & $6(100 \%)$ \\
\hline & $6(2007)$ & $1246 \mathrm{Y}$ & mutant & $25(49 \%)$ & $0(0 \%)$ \\
\hline & 50 (1999) & NYD & wild-type & $2(4 \%)$ & $0(0 \%)$ \\
\hline & $6(2007)$ & NFD & single-mutant 1 & $4(8 \%)$ & $4(67 \%)$ \\
\hline & & FYD & single-mutant 2 & $2(4 \%)$ & $0(0 \%)$ \\
\hline & & NYY & single-mutant 3 & $1(2 \%)$ & $0(0 \%)$ \\
\hline & & YYD & single-mutant 4 & 15 (30\%) & $2(33 \%)$ \\
\hline & & YYY & double-mutant 1 & $19(38 \%)$ & $0(0 \%)$ \\
\hline & & NFY & double-mutant 2 & $4(8 \%)$ & $0(0 \%)$ \\
\hline & & YFD & double-mutant 3 & $2(4 \%)$ & $0(0 \%)$ \\
\hline & & YFY & triple-mutant & $1(2 \%)$ & $0(0 \%)$ \\
\hline \multirow{5}{*}{$\begin{array}{l}\text { pfdhfr } \\
\text { Amino acids: } \\
50,51,59,108,164\end{array}$} & 34 (1999) & CNCSI & wild-type & $3(8 \%)$ & $1(17 \%)$ \\
\hline & $6(2007)$ & CNCSI/CIRNI & mixed & $0(0 \%)$ & $1(17 \%)$ \\
\hline & & CIRNI & triple-mutant & $28(82 \%)$ & $3(50 \%)$ \\
\hline & & CIRNI/CIRNL & mixed & $0(0 \%)$ & $1(17 \%)$ \\
\hline & & CIRNI/CICNI & mixed & $3(10 \%)$ & $0(0 \%)$ \\
\hline \multirow{2}{*}{$\begin{array}{l}\text { Pfdhps } \\
\text { Amino acids: } \\
\text { 436, 437, 540, 581,613. }\end{array}$} & 27 (1999) & SAKAA & wild-type & 25 (93\%) & $6(100 \%)$ \\
\hline & 6 (2007) & SGEAA & double-mutant & $2(7 \%)$ & $0(0 \%)$ \\
\hline \multirow[t]{3}{*}{ pfdhr \& pfdhps } & 23 (1999) & CNCSI/SAKAA & & $3(13 \%)$ & $1(17 \%)$ \\
\hline & $6(2007)$ & CIRNI/SAKAA & & $18(78 \%)$ & $5(83 \%)$ \\
\hline & & CIRNI/SGEAA & quintuple-mutant & $2(9 \%)$ & $0(0 \%)$ \\
\hline
\end{tabular}

NB: CIRNI/CIRNL, CIRNI/CICNI and CNCSI/CIRNI mixed haplotypes have been grouped into CIRNI for analysis of the prevalence of combined dhfr/dhps mutant haplotypes. $n=$ number of successfully genotyped samples. Mutant alleles are in bold for ease of identification. 
1034 and 1042 in any isolates. Therefore, analysis was concentrated on codons 86, 184 and 1246 of pfmdr 1 . Prevalence of the wild-type $p f m d r 1-86 \mathrm{~N}$ allele was $24 \%$ $(\mathrm{n}=51)$ in 1999 and 67\% in $2007(\mathrm{n}=6)$. Unexpectedly, a novel mutation showing substitution of asparagine $(\mathrm{N})$ with phenylalanine $(\mathrm{F})$, rather than the common tyrosine (Y) substitution, at the 86 position was observed in two (4\%) of the 1999 isolates from Swaziland. This mutation has not been described in natural field isolates before, but has been observed in two mefloquine-selected subclones of the laboratory isolate W2mef [27]. Its origin or implications are unknown. The mutant $184 \mathrm{~F}$ and $1246 \mathrm{Y}$ alleles were found in $11 / 50$ (22\%) and $25 / 51$ (49\%) respectively among 1999 samples. The $184 \mathrm{~F}$ allele showed an increase in prevalence from 22\% in 1999 to $67 \%$ in 2007 . The $1246 \mathrm{Y}$ allele was not observed among the 2007 isolates.

Nine different haplotypes were obtained from the analysis of the 86, 184 and 1246 codons (Table 2). The wild type $p f m d r 1-N Y D$ haplotype was observed in only two (4\%) of the 51 successfully sequenced 1999 samples but was not observed in any of the 2007 samples. The prevalence of the single-mutant YYD haplotype remained unchanged in the two years (33\% and 30\%, respectively). Prevalence of the NFD haplotype was only $8 \%$ in 1999 , but was $67 \%$ in 2007 . The double-mutant haplotype YYY was found in many of the 1999 samples $(19 / 50=$ $38 \%$ ) yet in none of the 2007 samples. This was also true of the NFY haplotype, which was found in 4/50 (8\%) of the 1999 samples but not in the 2007 samples (Figure 1). Other haplotypes occurred with low frequency in 1999 but were absent in 2007 and have not been shown in the Figure. These are YFD (4\%), NYY (2\%), FYD (4\%) and the triple-mutant haplotype YFY (2\%).

\section{Pfdhfr polymorphisms}

The 2007 isolates $(\mathrm{n}=6)$ were all successfully genotyped for pfdhfr mutations at codons 16, 50, 51, 59, 108 and 164, while the DNA samples obtained by scraping thick blood films from 1999 ran low: only 34 of the 73 isolates from 1999 (47\%) were successfully genotyped. The wild-type CNCSI haplotype was relatively uncommon, occurring in $8 \%$ of isolates in 1999 and $17 \%$ of isolates in 2007. Mixed infections, containing the triplemutant CIRNI and double-mutant CICNI, were observed in three (10\%) of the 1999 isolates. The prevalence of the CIRNI triple-mutant haplotype of the $d h f r$ gene was $82 \%$ ( 28 of 34 ) in 1999, and 50\% (3 of 6) in 2007, but a statistical test for evidence of a significant reduction is not presented due to the low number of isolates available for the 2007 analysis. Despite reports of the pfdhfr I164L mutation in eastern Africa [28], this allele was not found among Swaziland isolates. The prevalence of each $p f d h f r$ haplotype identified is shown in Table 2.

\section{Pfdhps polymorphisms}

Twenty-seven isolates from 1999 and all six isolates from 2007 were successfully genotyped for dhps mutations at the 431, 436, 437, 540, 581 and 613 codons. All the 2007 isolates were wild-type ISAKAA while $93 \%$ of the 1999 isolates carried this wild-type haplotype. The remaining $7 \%$ carried the double-mutant ISGEAA

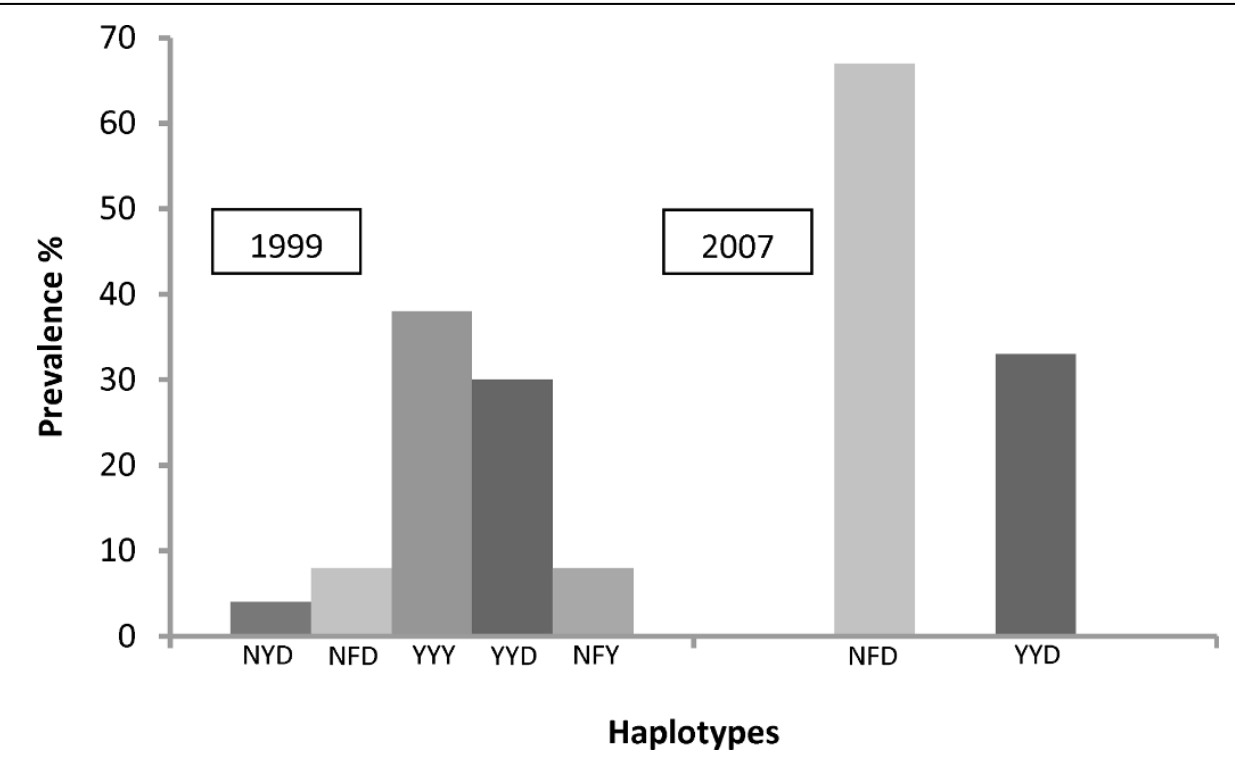

Figure 1 Prevalence of the five most common pfmdr 1 haplotypes at codons 84, 184 and 1246 among Swaziland $P$. falciparum isolates in $1999(\mathrm{~N}=50)$ and $2007(\mathrm{~N}=6)$. 
haplotype. The codon 431 mutation (I431V), recently described from Nigerian isolates [23], was not observed.

Twenty-three samples were successfully genotyped for both $d h f r$ and dhps mutations. The prevalence of the combined wild-type haplotype dhfr/dhps-CNCSI/ SAKAA was similar in 1999 (13\%) and 2007 (17\%). The triple-mutant haplotype $d h f r / d h p s$-CIRNI/ISAKAA also remained highly prevalent at 78\% (1999) and 83\% (2007) in the two years. Prevalence of the quintuple-mutation CIRNI/ISGEAA was 9\% (2 of 23) in 1999 and 0\% among the isolates collected in 2007. Other mutations in dhfr including S108T and A16V were not found in any of the isolates from Swaziland described herein.

\section{Discussion}

Malaria is still a major concern in Swaziland despite recent reports of significant reduction of disease incidence by more than 95\% [29]. Selection of effective and affordable anti-malarials for treatment and control remain extremely important and complicated in this era of emergence of $P$. falciparum parasites resistant to multiple anti-malarials. CQ failure in Swaziland was first reported in 1987 [1]. More than twenty years later, Swaziland retained CQ as a first-line anti-malarial for treating uncomplicated malaria. Although SP has not been used as a first-line anti-malarial in Swaziland, it is still of interest to determine whether parasites remain susceptible to the drug especially following reports of resistance from neighbouring countries. SP is used as a second-line anti-malarial for CQ resistant (CQR) parasites.

The high prevalence of the $p f c r t$ CVIET haplotype, which originated in CQR parasites from Southeast Asia [30,31], and the absence of CQR haplotype SVMNT (South American) among isolates examined in this study is consistent with the earlier presumed spread of CQR parasites from Southeast Asia to Africa via the Indian subcontinent. Reports of SVMNT occurrence described in isolated areas of East Africa are probably a result of resistance to $\mathrm{AQ}$ or its metabolite desethyl-amodiaquine (DEAQ) following use of AQ as monotherapy [32]. High prevalence of $76 \mathrm{~T}$ mutations both in 1999 and 2007 suggests that CQ resistance is widespread in Swaziland. Studies have also shown that acquisition of 76T mutations favours severity and multiplicity of malaria infection [33] and, together with $p f m d r 1$ mutations, is associated with life-threatening complications such as severe anaemia $(\mathrm{Hb}<5 \mathrm{~g} / \mathrm{dl})$ in young children [34].

No published data are available on the in vivo efficacy of CQ in Swaziland. Evidence of heavy over-prescription is described here, in which only six of 252 patients treated for malaria in 2007 proved to be parasite positive by both retrospective slide-reading and PCR. Previous studies elsewhere have shown that the $76 \mathrm{~T}$ and $86 \mathrm{Y}$ mutations occur among parasites surviving CQ treatment, including those responsible for production of transmissible gametocytes [35,36]. In CQ-treated children, parasites with $p f m d r 186 \mathrm{Y}$ and $p f c r t 76 \mathrm{~T}$ are transmitted more frequently than other genotypes and this mechanism probably supports continued circulation of these genotypes [37]. Further studies among malaria patients in Swaziland are required to estimate any impact of these mutations on treatment outcome. The pfmdr1$1246 \mathrm{Y}$ allele, found at $49 \%$ prevalence among 1999 isolates, was absent among 2007 isolates, suggesting withdrawal of CQ use may lead to further beneficial changes in the parasite population in Swaziland.

The novel 86F mutation in pfmdr1 identified in two samples from this study has not previously been described in field-collected parasites. In the isolates described here, the phenylalanine at position 86 is encoded by the codon UUU, which has two base changes from the wild-type asparagine codon AAU, but only a single base-change from the common CQ-resistance-associated tyrosine codon, UAU. The $86 \mathrm{~F}$ allele is therefore likely to have arisen from the $86 \mathrm{Y}$ form of pfmdr 1 by a single point mutation, rather than directly from the wild-type $86 \mathrm{~N}$ form, which would require a minimum of two changes. This is consistent with in vitro observations [27].

The absence of the wild-type pfmdr1-NYD haplotype in 2007 and its low prevalence among 1999 isolates suggest that CQ resistance had developed over a long time. The high prevalence of the $p f m d r 1$-NFD haplotype in 2007 and absence of the YYY haplotype is of interest, as studies elsewhere in Africa have reported selection for the NFD allele of $p f m d r 1$ and loss of the YYY allele following treatment with artemether-lumefantrine (AL) $[12,13]$. Since there is no history of AL use in Swaziland, this pattern may be a result of the impact of drug policy changes in neighbouring South Africa, KwaZulu-Natal $(\mathrm{KZN})$ and Mozambique. Swaziland is a very small country and the influence of drug policies in Mozambique and South Africa (KZN) cannot be ruled out. KZN introduced AL in 2001 while Mozambique introduced artesunate-sulphadoxine/pyrimethamine (AS-SP) combination therapy in 2002 and artesunate/AQ in 2004. Thus, deployment of AL in KZN and the introduction of AS-SP treatment policy in Mozambique could have influenced selection of $86 \mathrm{~N}$ parasites through successful transmission compared to their mutant counter-parts. However, this phenomenon can only be confirmed through analysis of a larger number of samples from Swaziland. Transmission studies reported a four-fold reduction in transmissibility to mosquitoes of the $86 \mathrm{Y}$ allele compared to the $86 \mathrm{~N}$ allele following addition of artesunate to CQ [35]. The same study reported an association between CQ monotherapy and increased $86 \mathrm{Y}$ transmissibility. Other studies have shown increased 
tolerance of laboratory parasite clones to mefloquine and halofantrine, (which are related to lumefantrine) if they carried the $86 \mathrm{~N}$ allele [10] or the $1034 \mathrm{~S} / 1042 \mathrm{~N} /$ 1246D haplotype [38]. Therefore, the prevalence of NFD haplotypes in Swaziland has to be closely monitored as it could compromise the effectiveness of combinations involving lumefantrine in the future. Unfortunately, data on the prevalence of NFD and YYY haplotypes in KZN following AL implementation in 2001 are not available.

Regional drug pressure, as well as prescription of SP to CQ-resistant cases probably partly explains the high prevalence of $d h f r$ triple-mutant haplotypes (82\%) observed in 1999 in Swaziland. The prevalence of the $d h f r$-CIRNI triple-mutant haplotype in Zone 1 in Southern Mozambique, the zone closest to Swaziland, was $47.5 \%$ in 1999 [39] which is lower than that observed in Swaziland, suggesting only partial influence from Mozambique, possibly because SP was in use in Swaziland as a second-line drug. In contrast, there was a high prevalence of the triple-mutant haplotype at Masvold Hospital in northern KZN [40] in 1999. The results given here suggest that the prevalence of $d h f r$ mutations in Swaziland was high compared to that in neighbouring countries. Thus, regional drug pressure alone may not explain allele prevalence in Swaziland. SP drug pressure in Swaziland may also have been further enhanced by the use of other anti-folate compounds, such as the combination antibiotic cotrimoxazole, which have crossresistance with SP. As HIV infection rates are high in Swaziland, cotrimoxazole is commonly prescribed as prophylaxis against opportunistic infections to HIV patients [2], and may have contributed to persistence of CIRNI triple-mutant malaria parasites in Swaziland.

The results presented here strongly support the recent move to replace CQ with the highly efficacious artemisinin-combination therapies (ACTs) in Swaziland. The replacement of presumptive treatment with a quick, simple and cheaper diagnostic method such as rapid diagnostic tests (RDTs) to reduce inappropriate prescription of drugs should reduce the cost of ACT drug and further delay development of resistance. Deployment of AL in Swaziland is likely to further reduce prevalence of YYY haplotype but could increase the NFD haplotype, and this may help preserve good AQ efficacy $[12,13,41]$, as will the recent withdrawal of AQ use in neighbouring Mozambique. In the absence of the pfmdr1 YYY haplotype, AQ shows in vivo and vitro efficacy against parasite clones with the CVIET pfcrt haplotype $[13,42]$; parasites of this genotype are shown here to be abundant in Swaziland.

\section{Conclusion}

This study is the first to document the presence and circulation of CQR parasites in Swaziland. The high prevalence of $p f c r t-76 \mathrm{~T}, p f m d r 1-86 \mathrm{Y}$, and $p f m d r 1-1246 \mathrm{Y}$ among 1999 isolates suggests that the population of isolates circulating in Swaziland has been selected by the long use of CQ. These findings thus strongly support the withdrawal of CQ as a first-line anti-malarial drug for uncomplicated $P$. falciparum malaria, and replacement with ACT. SP remains available for use in pregnant women, but the occurrence of the SGEAA haplotype in Swaziland, previously associated with resistance to sulphadoxine, suggests that SP use for treatment of uncomplicated malaria might rapidly select for these SP-resistant parasites. A weakness of this study is the small number of isolates obtained during the health facility survey in 2007. Genetic analysis of parasites from larger surveys in Swaziland and neighbouring countries is required for better understanding of the development of anti-malarial drug resistance in this region.

\section{Acknowledgements}

We thank the Ministry of Health and Social Welfare (Swaziland) and the Health centres in the Lowveld of Swaziland for allowing permission for the study. We also thank the nurses and laboratory technicians for their technical assistance. We are grateful to the patients who gave their consent to take part. Financial assistance was provided by the Commonwealth Scholarship Commission and Tropical Diseases Research (WHO). CJS is supported by the UK Health Protection Agency.

\section{Author details}

${ }^{1}$ Faculty of Health Sciences, University of Swaziland, Mbabane, Swaziland. ${ }^{2}$ Department of Infectious and Tropical Diseases, London School of Hygiene and Tropical Medicine, Keppel St, London WC1E 7HT, UK.

\section{Authors' contributions}

SD and CJS conceived the study. SD performed fieldwork. SD and KB performed laboratory work. SD and CJS analysed data. All authors contributed to the paper, and approved the final manuscript.

\section{Competing interests}

The authors declare that they have no competing interests.

Received: 27 July 2009 Accepted: 3 March 2010

Published: 3 March 2010

\section{References}

1. Raviglione MC: Appearance of chloroquine-resistant falciparum malaria in Swaziland. Lancet 1987, 2:44-45.

2. White NJ: Antimalarial drug resistance. J Clin Invest 2004, 113:1084-1092.

3. Franco ALT, Schwalback J, Fernandes A, Schapira A: Existencia in Mozambique de malaria $P$. falciparum resistance a chloroquine (19831984). Revista Medica de Mozambique 1984, 2:83-85.

4. Schapira A, Schwalback JFL: A malaria resistante em Mocambique. Epidemiology e control 1983-1987. Instituto Nacionale de Saude, Maputo. In: Abacassamo et al. 2004. Efficacy of chloroquine, amodiaquine, sulphadoxine-pyrimethamine and combination therapy with artesunate in Mozambican children with non-complicated malaria [Abstract]. Trop Med Int Health 1989, 9:200-208.

5. Schapira A, Schwalback J: Evaluation of four therapeutic regimens for falciparum malaria in Mozambique, 1986. Bull World Health Organ 1988, 66:219-226.

6. Freese JA, Sharp BL, Ngxongo SM, Markus MB: In vitro confirmation of chloroquine-resistant Plasmodium falciparum malaria in KwaZulu. S Afr Med J 1988, 74:576-578.

7. Fidock DA, Nomura T, Talley AK, Cooper RA, Dzekunov SM, Ferdig MT, Ursos LM, Sidhu AB, Naude B, Deitsch KW, Su XZ, Wootten JC, Roepe PD, 
Wellems TE: Mutations in the $P$. falciparum digestive vacuole transmembrane protein pfcrt and evidence for their role in chloroquine resistance. Mol Cell 2000, 6:861-871.

8. Hastings IM, Bray PG, Ward SA: A requiem for chloroquine. Science 2002, 298:74-75.

9. Foote S, Kyle D, Martin R, Oduola A, Forsyth K, Kemp D, Cowman A: Several alleles of the multi drug-resistance gene are closely linked to chloroquine resistant Plasmodium falciparum. Nature 1990, 345:255-258.

10. Duraisingh MT, Jones $P$, Sambou I, von Seidlein L, Pinder M, Warhurst DC: The tyrosine-86 allele of the pfmdr1 gene of Plasmodium falciparum is associated with increased sensitivity to the antimalarials mefloquine and artemisinin. Mol Biochem Parasitol 2000, 108:13-23.

11. Reed MB, Saliba K, Caruana SR, Kirk K, Cowman AF: Pgh1 modulates sensitivity and resistance to multiple antimalarials in Plasmodium falciparum. Nature 2000, 403:906-909.

12. Sisowath C, Stromberg J, Martensson A, Msellem M, Obondo C, Bjorkman A, Gil JP: In vivo selection of Plasmodium falciparum pfmdr $186 \mathrm{~N}$ coding alleles by artemether-lumefantrine (Coartem). J Infect Dis 2005, 191:1014-1017.

13. Humphreys GS, Merinopoulos I, Ahmed J, Whitty CJM, Mutabingwa TK, Sutherland CJ, Hallett R: Amodiaquine and Artemether-Lumefantrine Select Distinct Alleles of Plasmodium falciparum mdr1 Gene in Tanzanian Children Treated for Uncomplicated malaria. Antimicrob Agents Chemother 2007, 51:991-997.

14. Price $R N$, Uhleman $A C$, van Vugt $M$, Brockman $A$, Hatagalung $R$, Nair $S$, Nash D, Singhasivanon P, Anderson TJC, Krishna S, White NJ, Nosten F: Molecular and pharmacological determinants of the therapeutic response to artemether-lumefantrine in multi-drug resistant Plasmodium falciparum malaria. Clin Infect Dis 2006, 42:1570-1577.

15. Peterson DS, Walliker D, Wellems TE: Evidence that a point mutation in dihydrofolate reductase-thymidylate synthase confers resistance to pyrimethamine in falciparum malaria. Proc Natl Acad Sci USA 1988, 85:9114-9118.

16. Triglia T, Menting JG, Wilson C, Cowman AF: Mutations in dyhydropteroate synthase are responsible for sulfone and sulphonamide resistance in Plasmodium falciparum. Proc Natl Acad Sci USA 1997 94:13944-13949.

17. Cowman A, Morry MJ, Biggs BA, Cross GAM, Foote SJ: Amino acid changes linked to pyrimethamine resistance in the dihydrofolate reductasethymidylate synthase gene of Plasmodium falciparum. Proc Natl Acad Sci USA 1988, 85:9109-9113.

18. Hyde JE: The dihydrofolate reductase-thymidylate synthetase gene in the drug resistance of malaria parasites. Pharmacol Ther 1990, 48:45-49.

19. Brooks R, Wang P, Read M, Watkins MW, Sims PFG, Hyde JE: Sequence variation of the hydroxymethyldihydropterin pyrophosphokinase: dihydropteroate synthase gene lines of the human malaria parasite, Plasmodium falciparum, with differing resistance to sulfadoxine. $J$ Biochem 1994, 224:397-405.

20. Triglia T, Cowman A: Primary structure and expression of the dihydropteroate synthetase gene of Plasmodium falciparum. Proc Nat Acad Sci USA 1994, 91:7149-7153.

21. Plowe CV, Cortese JF, Djimdé A, Nwanyanwu OC, Watkins WM, Winstanley PA, Estrada-Franco JG, Mollinedo RE, Avila JC, Cespedes JL, Carter D, Doumbo OK: Mutations in Plasmodium falciparum dihydrofolate reductase and dyhydopteroate synthetase and epidemiologic patterns of sulfadoxine-pyrimethamine use and resistance. J Infect Dis 1997, 176:1590-1596.

22. Kublin JG, Witzig RS, Shankar AH, Zurita JQ, Gilman RH, Guarda JA, Cortese JF, Plowe CV: Molecular assays for surveillance of antifolate resistant malaria. Lancet 1998, 351:1629-1630.

23. Sutherland CJ, Fifer $H$, Pearce RJ, bin Reza F, Nicholas M, Haustein T, Njimgye-Tekumafor NE, Doherty JF, Gothard P, Polley SD, Chiodini PL Novel pfdhps haplotypes among imported cases of Plasmodium falciparum malaria in the UK. Antimicrob Agents Chemother 2009, 53:3405-3410

24. Plowe CV, Djimdé A, Bouare M, Doumbo O, Wellems TE: Pyrimethamine and proguanil resistance-conferring mutations in Plasmodium falciparum dihydrofolate reductase: polymerase chain reaction methods for surveillance in Africa. Am J Trop Med Hyg 1995, 52:565-568.

25. Sutherland CJ, Haustein T, Gadalla N, Armstrong M, Doherty JF, Chiodini PL: Chloroquine-resistant Plasmodium falciparum infections among UK travellers returning with malaria after chloroquine prophylaxis. J Antimicr Chemother 2007, 59:1197-1199.

26. Pearce RJ, Drakeley C, Chandramohan D, Mosha F, Roper C1: Molecular determination of point mutation haplotypes in the dihydrofolate reductase and dihydropteroate synthase of Plasmodium falciparum in three districts of Northern Tanzania. Antimicrob Agents Chemother 2003, 47:1347-1354.

27. Cowman AF, Galatis D, Thompson JK: Selection for mefloquine resistance in Plasmodium falciparum is linked to amplification of the pfmdrl gene and cross-resistance to halofantrine and quinine. Proc Natl Acad Sci USA 1994, 91:1143-1147.

28. Alker AP, Mwapasa V, Purfield A, Rogerson SJ, Molyneux ME, Kamwendo DD, Tadesse E, Chaluluka E, Meshnick SR: Mutations associated with sulfadoxine-pyrimethamine and chlorproguanil resistance in Plasmodium falciparum isolates from Blantyre, Malawi. Antimicrob Agents Chemother 2005, 49:3919-3921.

29. Sharp BL, Kleinschimidt I, Streat E, Maharaj R, Barnes Kl, Durrheim DN, Ridl FR, Morris N, Seocharan I, Kunene S, LaGrange JJP, Mthembu JD, Martens F, Martin CL, Barreto A: Seven years of regional malaria control collaboration-Mozambique, South Africa and Swaziland. Am J Trop Med Hyg 2007, 76:42-47.

30. Djimdé A, Doumbo OK, Cortese JF, Kayentao K, Doumbo S, Diourté Y, Dicko A, Su X, Nomura T, Fidock DA, Wellems TE, Plowe CV: A molecular marker for chloroquine resistant falciparum malaria. N Engl J Med 2001, 344:257-263.

31. Wootton JC, Feng X, Ferdig MT, Cooper RA, Mu J, Baruch DI, Magill AJ, Su XZ: Genetic diversity and chloroquine selective sweeps in Plasmodium falcip arum. Nature 2002, 418:320-323.

32. Alifrangis $M$, Dalgaard MB, Lusingu JP, Vestergaard LS, Staalsoe $T$, Jensen AT, Enevold A, Ronn AM, Khalil IF, Warhurst DC, Lemnge MM, Theander TG, Bygbjerg IC: Occurrence of the South Asian/South American SVMNT haplotype of the chloroquine-resistance transporter gene in Plasmodium falciparum in Tanzania. J Infect Dis 2006, 193:1738-1741.

33. Ranjit MR, Das A, Chhotray GP, Das BN, Acharya AS: The pfcrt (K76T) point mutation favours clone multiplicity and disease severity in Plasmodium falciparum infection. Trop Med Int Health 2004, 9:857-861.

34. Meerman L, Ord R, Teun Bousema J, van Niekerk M, Osman E, Hallett R, Pinder M, Walraven G, Sutherland CJ: Carriage of chloroquine-resistant parasites and delay of effective treatment increase the risk of severe malaria in Gambian children. J Infect Dis 2005, 192:1651-1657.

35. Hallett RL, Sutherland CJ, Alexander N, Ord R, Jawara M, Drakeley CJ, Pinder M, Walraven G, Targett GAT, Alloueche A: Combination therapy counteracts the enhanced transmission of drug resistant malaria parasites to mosquito. Antimicrob Agents Chemother 2004, 48:3940-3943.

36. Hallett RL, Dunyo S, Ord R, Jawara M, Pinder M, Randall A, Alloueche A, Walraven G, Targett GAT, Alexander N, Sutherland CJ: Chloroquine/ sulphadoxine-pyrimethamine for gambian children with malaria: transmission to mosquitoes of multidrug-resistant Plasmodium falciparum. PLoS Clin Trials 2006, 1:e15, DOl; 10.1371/journal.pctr.0010015.

37. Sutherland CJ, Alloueche A, Curtis J, Drakeley CJ, Ord R, Duraisingh M, Greenwood B, Pinder M, Warhurst D, Targett GAT: Gambian children successfully treated with chloroquine can harbour and transmit Plasmodium falciparum gametocytes carrying resistant genes. Am J Trop Med Hyg 2002, 67:578-585.

38. Sidhu $A B$, Valderramos SG, Fidock DA: Pfmdr1 mutations contribute to quinine resistance and enhance mefloquine and artemisinin sensitivity in Plasmodium falciparum. Mol Microbiol 2005, 57:913-926.

39. Raman J, Sharp B, Kleinschimidt I, Roper C, Streat E, Kelly V, Barnes KI: Differential effect of regional drug pressure on dihydrofolate reductase and dihydrofolate synthetase mutations in southern Mozambique. Am J Trop Med Hyg 2008, 78:256-261.

40. Roper C, Pearce R, Bredenkemp B, Gumede J, Drakeley C, Mosha F, Chandramohan D, Sharp B: Antifolate antimalarial resistance in southeast Africa: a population-based analysis. Lancet 2003, 361:1174-1181. 
41. Holmgren G, Hamrin J, Svärd J, Mårtensson A, Pedro Gil J, Björkman A: Selection of pfmdr1 mutations after amodiaquine monotherapy and amodiaquine plus artemisinin combination therapy in East Africa. Infect Gen Evol 2007, 7:562-569.

42. Sidhu $A B$, Verdier-Pinard $D$, Fidock DA: Chloroquine resistance in Plasmodium falciparum malaria parasites conferred by pfcrt mutations. Science 2002, 298:210-213.

doi:10.1186/1475-2875-9-68

Cite this article as: Dlamini et al:: Markers of anti-malarial drug resistance in Plasmodium falciparum isolates from Swaziland: identification of pfmdr1-86F in natural parasite isolates. Malaria Journal 2010 9:68.

Submit your next manuscript to BioMed Central and take full advantage of:

- Convenient online submission

- Thorough peer review

- No space constraints or color figure charges

- Immediate publication on acceptance

- Inclusion in PubMed, CAS, Scopus and Google Scholar

- Research which is freely available for redistribution

Submit your manuscript at www.biomedcentral.com/submit
C Biomed Central 